\title{
Recurrent pericarditis caused by familial Mediterranean fever: A case report
}

\author{
D ${ }^{1}$ Ali KARAMAN \\ (D) ${ }^{2}$ Doğan Nasır BíNici
}

${ }^{1}$ University of Health Sciences, Zeynep Kamil Women and Children Training and Research Hospital, Genetic Diagnosis Center, İstanbul, Turkey ${ }^{2}$ Department of Internal Medicine, University of Health Sciences, Erzurum Training and Research Hospital, Erzurum, Turkey

\section{ORCID ID}

AK : 0000-0003-1691-0781

DNB : 0000-0002-1614-7707

\begin{abstract}
Familial Mediterranean fever (FMF) is characterized by clinically recurrent fever attacks and inflammation associated with serositis. The Mediterranean fever gene is found in 16p13.3 and its mutations are known to lead to FMF. Here, we present a patient with FMF and recurrent pericarditis who responded to colchicine treatment. Therefore, regular follow-up of FMF patients who are mutation carriers is important in terms of cardiovascular risk.
\end{abstract}

Keywords: Familial Mediterranean fever, Mediterranean fever gene, recurrent pericarditis.

Cite this article as: Karaman A, Binici DN. Recurrent pericarditis caused by familial Mediterranean fever: A case report. Zeynep Kamil Med $\mathrm{J}$ 2021;52(1):49-52.

Received: December 04, 2020 Accepted: February 22, 2021 Online: March 31, 2021

Correspondence: Ali KARAMAN, MD. Zeynep Kamil Kadın ve Çocuk Hastalıkları Eğitim ve Araştırma Hastanesi,

Genetik Tanı Merkezi, İstanbul, Turkey.

Tel: +90 2163910680 e-mail: alikaramandr@hotmail.com

๑) Copyright 2021 by Zeynep Kamil Medical Journal - Available online at www.zeynepkamilmedj.com 


\section{INTRODUCTION}

Familial Mediterranean fever (FMF) is an autosomal recessive disorder and frequently observed among the nations of the Mediterranean populations, such as Jews, Armenians, Turks, and Arabs. ${ }^{[1]}$

Mediterranean fever gene (MEFV) resides on $16 \mathrm{p} 13.3$ and its mutations are known to lead to FMF. MEFV encodes a protein called pyrin. The pyrin protein has a role in regulation of apoptosis, inflammation. MEFV consists of 10 exons and most patients have mutations associated with exon 10. M694V, V726A, M680I, and M694I (in exon 10) are common mutations that lead to FMF and are responsible for more than $80 \%$ of FMF cases in the Middle Eastern region. ${ }^{[2]}$

FMF is clinically characterized by recurrent episodes of fever and inflammation associated with serositis. Usually, peritonitis is typically the first manifestation of FMF. Other findings of FMF are synovitis, pleuritis, and rarely pericarditis and meningitis. The incidence of pericarditis in FMF is low, ranging between $0.7 \%$ and $1.4 \%{ }^{[3,4]}$ Recurrent pericarditis as the initial finding has been reported in a few case with FMF. ${ }^{[5-7]}$

Here, we report a patient with suspected FMF and recurrent pericarditis who responded to colchicine therapy.

\section{CASE REPORT}

A 27-year-old Turkish man applied to the emergency department with acute chest pain, which was aggravated with deep inspiration and rotation. There is no history of cigarette, alcohol, and drug use. Serum C-reactive protein (CRP) was $12 \mathrm{mg} / \mathrm{dl}$. Electrocardiogram showed normal sinus rhythm, however, echocardiogram revealed mild pericardial effusion. The patient was diagnosed with acute pericarditis and indomethacin $800 \mathrm{mg} /$ day was administered. CRP level decreased to $1.1 \mathrm{mg} / \mathrm{dl}$. Chest pain was relieved and the patient was discharged.

Three weeks later, the patient applied to the emergency department with similar chest pain. At the time of admission, the patient's temperature, pulse rate, and blood pressure were normal. His heart sounds were clear without audible murmurs or pericardial friction rub. His breath sounds were normal, and no crackles were detected. Serum CRP was increased $(27.16 \mathrm{mg} / \mathrm{dl})$ and showed slightly increased

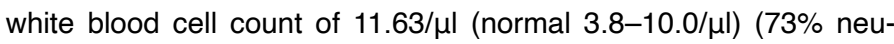
trophils, $16.3 \%$ lymphocytes, $8.4 \%$ monocytes, $2.1 \%$ eosinophils, and $0.2 \%$ basophils). Serum alanine aminotransferase was mildly elevated at $98 \mathrm{IU} / \mathrm{I}$ (12-55 IU/I), however, aspartate aminotransferase, lactate dehydrogenase, and gamma-glutamyl transferase levels were normal. In addition, serum protein electrophoresis showed an acute-phase pattern. Serum-free triiodothyronine and free thyroxine were within the normal ranges.

Echocardiogram showed only mild pericardial effusion. Computed tomography of the chest showed mild pericardial effusion with mild left pleural effusion.

During this second episode of pericarditis, indomethacin 800 $\mathrm{mg} /$ day and colchicine $1 \mathrm{mg} /$ day were started. As the patient's symptoms did not improve, colchicine dose was increased to $2 \mathrm{mg} /$ day. With this treatment continued for 12 months, his complaints disappeared, and all laboratory values were within normal limits and no episodes of pericarditis recurred. The sequencing MEFV gene revealed compound heterozygous mutation for M694V/R202Q. We performed MEFV mutation analysis on the patient's parents. The mother had a heterozygous M694V mutation. The father had a heterozygous $\mathrm{R} 202 \mathrm{Q}$ mutation.

\section{DISCUSSION}

Idiopathic recurrent pericarditis (IRP) is defined as repeated episodes of acute pericarditis with unknown origin. ${ }^{[8]}$ Autoimmune and autoinflammatory mechanisms have been accounted for the etiology of IRP. The safety and efficacy of colchicine have been shown in patients with recurrent pericarditis and colchicine decreases the recurrence rate after the first attack of acute pericarditis. ${ }^{[9,10]}$

Recurrent pericarditis can present as the only initial findings of FMF. Okutur et al. ${ }^{[5]}$ described a 25-year-old Turkish woman who presented with IRP. After a few episodes, she was treated with colchicine and episodes of pericarditis were terminated. MEFV mutation analysis showed that this patient was compound heterozygous for M694V and M680I.

Tutar et al. ${ }^{[6]}$ described an 8-year-old Turkish girl who had three attacks of pericarditis within a 3-month period. After the third attack, colchicine was started, which ended the episodes of pericarditis. During the subsequent 20 months under the colchicine treatment, no FMF attacks or acute pericarditis episodes were observed. She was compound heterozygous for E148Q and L695A.

Yoshioka et al. ${ }^{[7]}$ described a 56-year-old man who had a high fever, CRP level, and periodic episodes of acute pericarditis. The patient was treated with colchicine, became afebrile and CRP level decreased. No recurrence was shown. MEFV mutation analysis showed compound heterozygosity for E84K and G304R.

Our patient's MEFV mutation analysis showed compound heterozygosity for M694V and R202Q. M694V is the most commonly mutation in the Turkish population. Tunca et al. ${ }^{[4]}$ reported that $51.4 \%$ of 1090 FMF patients had M694V mutation in Turkish population, which is followed by M680I (14.4\%) and V726A (8.6\%). Another study by Yilmaz et al. ${ }^{[11]}$ reported that the allele frequency in FMF patients was $51.1 \%$ for M694V. M694V homozygosity is associated with a severe form of the disease and the most serious complication of the disease, amyloidosis, is reported at a higher incidence in cases homozygous for M694V. ${ }^{[12]}$

$\mathrm{R} 202 \mathrm{Q}$ has previously been reported as a common polymorphism. ${ }^{[13]}$ However, its clinical significance is still controversial. No significant association was found between demographic and clinical characteristics of patients and R202Q genotype in some studies. ${ }^{[14-16]}$

Yigit et al. ${ }^{[15]}$ reported that there was a high association between the R202Q and FMF, however, they state that $R 202 Q$ may not have an effect on disease in heterozygous state but can be a cause of illness in homozygous state and should be included in routine mutation screening of FMF.

In one study from Greece, Giaglis et al. ${ }^{[16]}$ showed that R202Q homozygosity was found in $48 \%$ of cases with FMF in whom no other MEFV mutation could be detected. Researcher supports that $\mathrm{R} 202 \mathrm{Q}$ polymorphism may have a diagnostic correlation in the homozygous state. 


\section{Table 1: Causes of pericarditis}

Idiopathic pericarditis

Infectious pericarditis

Autoimmune/vasculitis

Metabolic

Neighboring tissue diseases

Neoplasms

Trauma
Pericardial fat necrosis, Loffler syndrome, Thalassemia, drug reactions (procainamide, hydralazine)

Viral: Coxsackie A and B, influenza, HIV, hepatitis A, B, C

Bacterial: Tuberculosis, Streptococcus, Pneumococcus

Mushrooms

Parasitic: Ekinokok, Entamocba histolytica, cysticercus

Other: Rickettsial, spiroketal, mycoplasma, infectious mononucleosis

Rheumatoid arthritis, rheumatic fever, SLE, scleroderma, Sjögren syndrome, Reiter's syndrome, ankylosing spondylitis, Wegener granulomatosis, Behçet's syndrome, FMF, polyarteritis nodosa

Renal failure, myxedema, gout, skorbit

Myocardial infarction, aortic dissection, pleural and pulmonary disease

Mesothelioma, sarcoma, fibroma, metastatic, carcinomas, sarcomas

Penetrating, iatrogenic, radiation, dissecting aneurysm

FMF: Familial Mediterranean fever.

R202Q mutation located at exon 2 of the MEFV gene, which was reported as a frequent polymorphism with linkage disequilibrium with M694V mutation (http://fmf.igh.cnrs.fr/infevers/). In the study of Oztürk et al., ${ }^{[13]} \mathrm{R} 202 \mathrm{Q}$ was observed in a different haplotype which is not in linkage with M694V mutation. This denoted that it might be a disease-causing mutation. This may also confirm their hypothesis in two cases with amyloidosis. The R202Q frequency is high in their control group. It seems that it has no effect when it is in heterozygous state, however, when combined with another disease-causing mutation, the clinical spectrum appears. This shows that R202Q alteration is important for diagnosis.

Chronic pericarditis is a disease that maintains its importance today due to various etiological reasons. It may progress with non-specific symptoms and present with a serious clinical picture such as cardiac tamponade. Histological, cytological, and biochemical examinations are performed for diagnosis. Diagnosis and treatment processes are mostly carried out together. The classification of pericarditis for etiology is shown in Table 1. ${ }^{[17]}$

Pro-inflammatory cytokines and acute-phase reactants increase during FMF attacks. Therefore, it is thought that chronic inflammation that occurs may also be associated with increased cardiovascular risk in patients with FMF. ${ }^{[18]}$ In the study conducted by Salah et al. ${ }^{[19]}$ with pediatric patients diagnosed with FMF, it showed that approximately half of the patients affected by valvular disease. In another study, different degrees of tricuspid regurgitation were reported. [20]

In a recent study, two patients diagnosed with FMF and their family members evaluated in terms of cardiovascular involvement. In echocardiographic examination, different degrees of valvular insufficiency were reported. In addition, considering that all family members with the compound M694V, R202Q mutation has at least one cardiac valve disease, it can be said that it is important to follow these mutation carrier FMF patients in terms of cardiovascular involvement. ${ }^{[21]}$

According to these studies, M694V/R202Q mutation may suggest etiology of recurrent pericarditis in our patient. Mutation analysis of MEFV gene should keep in mind in patient with IRP to provide a proper diagnosis and treatment.

\section{Statement}

Informed Consent: Written informed consent was obtained from patients who participated in this study.

Peer-review: Externally peer-reviewed.

Author Contributions: Concept - AK, DNB; Design - AK, DNB; Supervision - AK, DNB; Resource - AK, DNB; Materials - AK, DNB; Data Collection and/or Processing - AK, DNB; Analysis and/or Interpretation - AK; Literature Search - AK; Writing - AK; Critical Reviews - AK, DNB.

Conflict of Interest: The authors have no conflict of interest to declare.

Financial Disclosure: The authors declared that this study has received no financial support.

\section{REFERENCES}

1. Onen F. Familial Mediterranean fever. Rheumatol Int 2006;26(6):48996.

2. Ben-Chetrit E, Touitou I. Familial Mediterranean fever in the world. Arthritis Rheum 2009;61(10):1447-53.

3. Kees S, Langevitz P, Zemer D, Padeh S, Pras M, Livneh A. Attacks of pericarditis as a manifestation of familial Mediterranean fever (FMF). QJM 1997;90(10):643-7.

4. Tunca M, Akar S, Onen F, Ozdogan H, Kasapcopur O, Yalcinkaya F, et al. Familial Mediterranean fever (FMF) in Turkey: Results of a nationwide multicenter study. Medicine (Baltimore) 2005;84(1):1-1.

5. Okutur K, Seber S, Oztekin E, Bes C, Borlu F. Recurrent pericarditis as the initial manifestation of Familial Mediterranean fever. Med Sci Monit 2008;14(12):CS139-41.

6. Tutar HE, Imamoglu A, Kendirli T, Akar E, Atalay S, Akar N. Isolated recurrent pericarditis in a patient with familial Mediterranean fever. Eur $\mathrm{J}$ Pediatr 2001;160(4):264-5.

7. Yoshioka K, Furumitsu Y, Sano T, Miyamoto T, Agematsu K. Acute pericarditis as the first manifestation of familial Mediterranean fever: $A$ possible relationship with idiopathic recurrent pericarditis. Intern Med 2014;53(15):1659-63.

8. Brucato A, Imazio M, Cremer PC, Adler Y, Maisch B, Lazaros G, et al. 
Recurrent pericarditis: Still idiopathic? The pros and cons of a well-honoured term. Intern Emerg Med 2018;13(6):839-44.

9. Imazio M, Brucato A, Cemin R, Ferrua S, Belli R, Maestroni S, et al. Colchicine for recurrent pericarditis (CORP): A randomized trial. Ann Intern Med 2011;155(7):409-14.

10. Imazio M, Belli R, Brucato A, Cemin R, Ferrua S, Beqaraj F, et al. Efficacy and safety of colchicine for treatment of multiple recurrences of pericarditis (CORP-2): A multicentre, double-blind, placebo-controlled, randomised trial. Lancet 2014;383(9936):2232-7.

11. Yilmaz E, Ozen S, Balci B, Duzova A, Topaloglu R, Besbas N, et al. Mutation frequency of Familial Mediterranean Fever and evidence for a high carrier rate in the Turkish population. Eur J Hum Genet 2001;9(7):553-5.

12. Akpolat T, Özkaya O, Özen S. Homozygous M694V as a risk factor for amyloidosis in Turkish FMF patients. Gene 2012;492(1):285-9.

13. Ozturk A, Özçakar B, Ekim M, Akar N, Mah K. Is MEFV gene Arg202GIn (605 G>A) a disease-causing mutation? Turk J Med Sci 2008;38(3):2048.

14. EIMesserya LO, Elhagrasy HF. Study of MEFV gene R202Q polymorphism in Egyptian patients with familial Mediterranean fever. Egypt $\mathrm{J}$ Haematol 2014;39(2):64-7.
15. Yigit S, Karakus N, Tasliyurt T, Kaya SU, Bozkurt N, Kisacik B. Significance of MEFV gene R202Q polymorphism in Turkish familial Mediterranean fever patients. Gene 2012;506(1):43-5.

16. Giaglis S, Papadopoulos V, Kambas K, Doumas M, Tsironidou V, Rafail $S$, et al. MEFV alterations and population genetics analysis in a large cohort of Greek patients with familial Mediterranean fever. Clin Genet 2007;71(5):458-67.

17. Ali VÖ, Melek D, İbrahim G, Kadir GS, Şükrü G, Okan C. Ailesel Akdeniz ateşinin neden olduğu kardiyak tamponad: Olgu sunumu. Türk Göğüs Kalp Damar Cerrahisi Derg 2012;20(3):632-5.

18. Shohat M, Halpern GJ. Familial Mediterranean fever--a review. Genet Med 2011;13(6):487-98.

19. Salah S, Hegazy R, Ammar R, Sheba H, Abdelrahman L. MEFV gene mutations and cardiac phenotype in children with familial Mediterranean fever: A cohort study. Pediatr Rheumatol Online J 2014;12:5.

20. Sargsyan A, Narimanyan M. Pulmonary hypertension in familial Mediterranean fever: Consequence or coincidence? Pediatr Rheumatol Online J 2015;13(1):O41.

21. Ibrahim HD, Recep E. Yeni ve nadir mutasyonlu FMF hastalarında kardiyak tutulum. Konuralp Tıp Derg 2019;11(2):274-7. 